\title{
ANÁLISE DO PROCESSO DE CONSTRUÇÃO DE UM AMBIENTE CONSTITUÍDO POR GARRAFAS PET
}

\author{
Daniel dos Santos Viais Neto ${ }^{1}$ \\ Camila Pires Cremasco Gabriel ${ }^{2}$ \\ Luís Roberto Almeida Gabriel Filho
}

RESUMO: O desenvolvimento tecnológico crescente associado a profundas mudanças no modo de vida contemporâneo tem gerado volumes de rejeitos cada vez maiores. Um desses rejeitos são as garrafas feita de PET. Essas garrafas podem ser aproveitadas para construções de ambientes em substituição dos tijolos. O objetivo deste trabalho foi estudar os aspectos necessários para a realização das obras de construção de um ambiente com materiais recicláveis analisando tipos, quantidades e custos dos materiais de construção e mão-de-obra. Além disso, criou-se estratégias para a arrecadação de garrafas pet, métodos de preenchimento das mesmas e mecanismos de divulgação do projeto intitulado "Projeto Casa Pet". O estudo comprovou que a garrafa pet pode substituir o tijolo, que um dos materiais adequados para preenche-las é o solo-cimento e que este tipo de construção tem despertado o interesse de pessoas de diversos locais do Brasil e até mesmo de outros países. Em futuros trabalhos, pretende-se comprovar que 0 ambiente é uma alternativa viável tanto do ponto de vista econômico e ambiental.

Palavras-chave: Sustentabilidade. Reciclagem. Plástico.

\footnotetext{
${ }^{1}$ FATEC - Faculdade de Tecnologia/Presidente Prudente, Professor Associado, Licenciado e Mestre em Matemática, Doutorando em Agronomia / Irrigação e Drenagem. dvneto@fatecpp.edu.br.

${ }^{2}$ FATEC - Faculdade de Tecnologia/Presidente Prudente, Professor Associado, Licenciada e Mestre em Matemática, Doutora Agronomia / Energia na Agricultura, Pós-Doutora em Biometria. camila.gabriel@fatec.sp.gov.br.

${ }^{3}$ UNESP - Univ Estadual Paulista, Campus Experimental de Tupã, Laboratório de Matemática Aplicada e Computacional, Professor Assistente Doutor, Licenciado e Mestre em Matemática, Doutor e Pós-Doutor em Agronomia / Energia na Agricultura. gabrielfilho@tupa.unesp.br.
} 


\section{INTRODUÇÃO}

O desenvolvimento tecnológico crescente associado a profundas mudanças no modo de vida contemporâneo tem gerado volumes de rejeitos cada vez maiores, os quais poderão se tornar um problema para a humanidade se não forem tomadas medidas para reduzir as quantidades encaminhadas diariamente para os lixões ou aterros sanitários. Como consequência destes eventos surgiram às leis ambientais e a sociedade como um todo passou por um processo de conscientização, levando as empresas e a própria sociedade a se preocuparem com a transformação de seus rejeitos em resíduos (OLIVEIRA; CASTRO, 2002).

Entre os diversos danos causados ao meio ambiente, pode-se destacar o resíduo plástico, que possui um tempo de degradação elevado e se queimados liberam gases tóxicos (ZANIN; MANCINI, 2004). Segundo Wiebeck e Harada (2005), a reciclagem é uma alternativa para reduzir o impacto ambiental da matéria-prima plástica descartada.

Entre estes tipos de matéria-prima descartada, encontram-se as garrafas feita de Polietileno Tereftalato (PET) que segundo a ABIPET (2011), mesmo com a taxa de recuperação de $\mathrm{PET}$ no Brasil aumentado ao longo dos últimos anos, parte dessas embalagens acaba sendo destinado aos lixões, sistema mais comum para disposição dos resíduos sólidos urbanos. Isto ocorre basicamente por dois motivos principais: a falta de coleta do lixo e os hábitos da população brasileira, que se desfaz dos seus resíduos jogando-os no lixo comum, não separando o material reciclável.

Alguns relatos mostram que essas garrafas podem ser aproveitadas para construções de ambientes em substituição dos tijolos. Acredita-se que a construção com garrafas pet pode reduzir o custo da obra em 2/3 do valor. A primeira casa brasileira construída com garrafas pet foi em Tarumirim - MG no ano de 2010 com $30 \mathrm{~m}^{2}$ de área útil e utilizando cerca de 10 mil garrafas (ABIPET, 2012).

O objetivo deste trabalho é estudar os aspectos necessários para a realização das obras de construção de um ambiente com materiais recicláveis analisando tipos, quantidades e custos dos materiais de construção e mão-de-obra. Além disso, criou-se estratégias para a arrecadação de garrafas pet, métodos de preenchimento das mesmas e mecanismos de divulgação do projeto intitulado "Projeto Casa Pet". A área a ser 


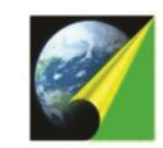

ANAP

utilizada para construção deste ambiente encontram-se nas dependências da Fatec de Presidente Prudente.

\section{METODOLOGIA}

Este trabalho foi elaborado a partir do Projeto Casa Pet, idealizado em 2012, mas que somente após vencer o $5^{\circ}$ Prêmio Instituto 3M para Estudantes Universitários em março de 2013 realizado pelo Instituto 3M de Inovação Social, começou a ser executado (Figura 1).

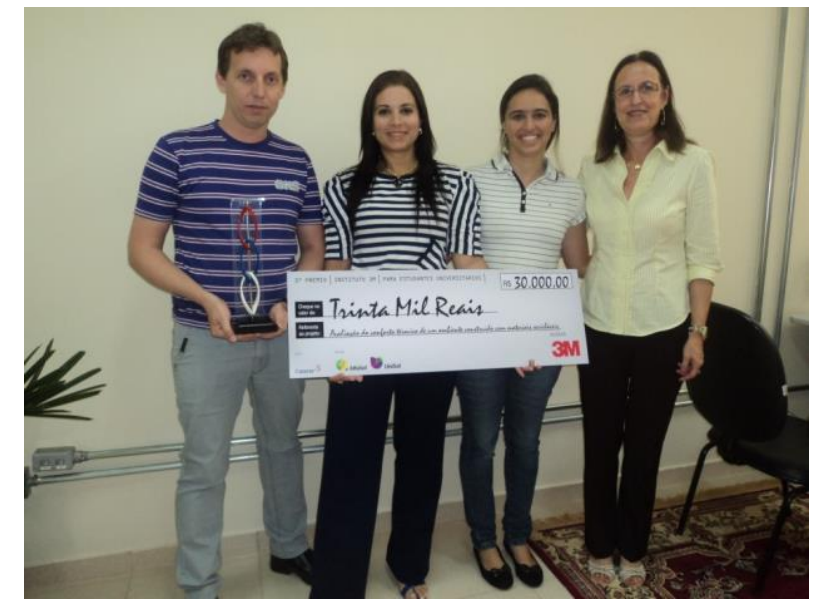

Figura 1. Prêmio recebido pelo Instituto $3 \mathrm{M}$ de Inovação Social.

O Projeto Casa Pet, que visa construir um ambiente de materiais recicláveis, está sendo desenvolvido na Fatec de Presidente Prudente. A Figura 2 mostra o local destinado a construção do ambiente. Este ambiente será designado por Casa Pet. 


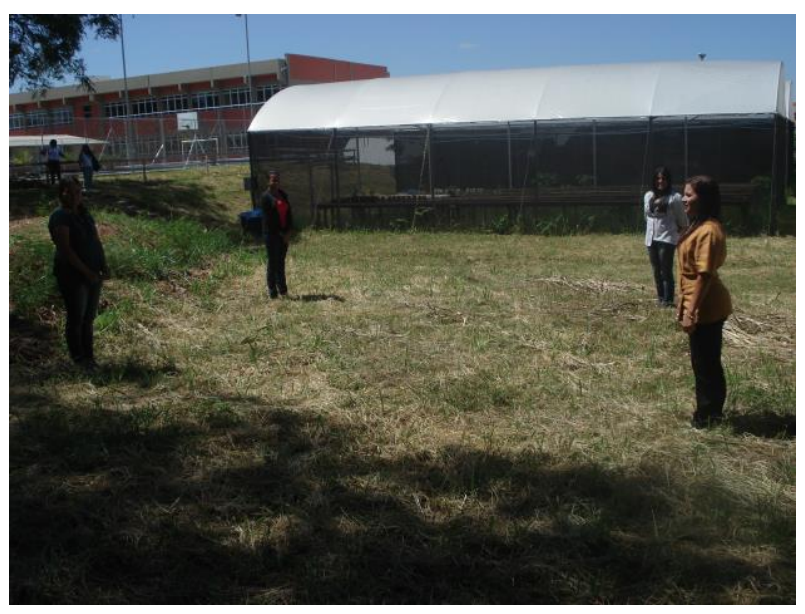

Figura 2. Foto do local de construção da Casa Pet.

A Casa Pet ocupará um espaço de $24 \mathrm{~m}^{2}$, sendo $16 \mathrm{~m}^{2}$ de sala e $8 \mathrm{~m}^{2}$ de área de serviço como mostra a planta-baixa (Figura 3 ).

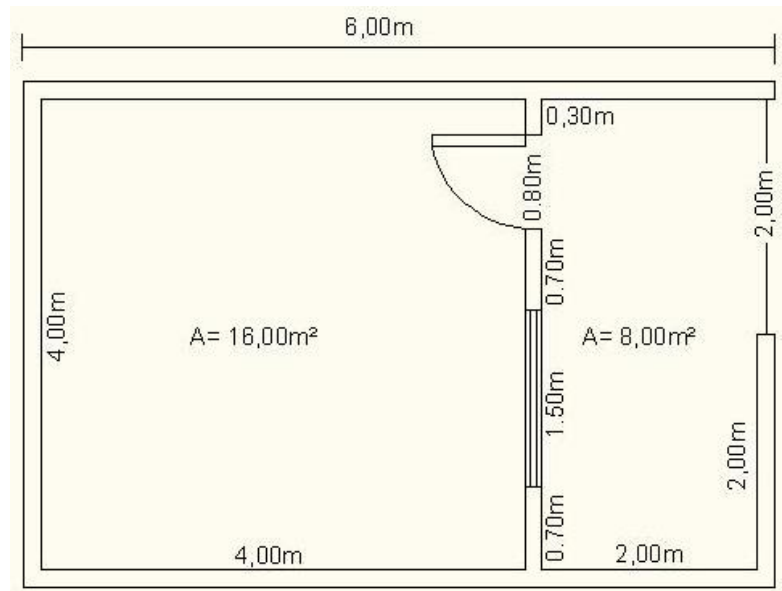

Figura 3. Planta-baixa da Casa Pet.

O levantamento de tipos, quantidades e custos dos materiais de construção e mãode-obra desta casa, foi feito consultando-se um especialista da área de construção civil e depósitos da cidade de Presidente Prudente.

Para a obtenção das garrafas pet por meio de doações foi realizada divulgação do projeto em salas de aula da Fatec de Presidente Prudente e na comunidade local. Além disso, foi feita uma parceria com um grupo de escoteiros da cidade.

Foram realizados testes de preenchimento de garrafas pet com areia, barro e solocimento (mistura de terra com cimento) para a verificação da rigidez do material. 
Para a divulgação das etapas do projeto, criou-se uma página em redes sociais.

\section{RESULTADOS E DISCUSSÃO}

A determinação da lista de materiais necessários para a construção do ambiente em questão foi obtida após consultas com especialistas da área de construção civil e, posteriormente, alunos envolvidos com o Projeto Casa Pet, fizeram uma pesquisa de preços nos depósitos de materiais de construção da cidade de Presidente Prudente obtendo um orçamento preliminar mostrado na Tabela 1. Já a mão-de-obra após pesquisa de preço, ficou orçada de $R \$ 100,00$ a $R \$ 150,00$ a diária de um pedreiro e de $R \$ 60,00$ a $\mathrm{R} \$ 80,00$ a diária de um ajudante de pedreiro.

Tabela 1. Orçamento financeiro do desenvolvimento do experimento.

\begin{tabular}{|c|c|c|c|}
\hline Itens de Dispêndio & Quantidade & $\begin{array}{c}\text { Preço } \\
\text { unitário }\end{array}$ & Preço total \\
\hline \multicolumn{4}{|l|}{ Capital } \\
\hline \multicolumn{4}{|l|}{ ESTRUTURA } \\
\hline Cimento (saco $50 \mathrm{~kg}$ ) & 25 & 25,00 & 625,00 \\
\hline Cal (saco $20 \mathrm{~kg})$ & 10 & 8,50 & 85,00 \\
\hline Areia lavada $\left(\mathrm{m}^{3}\right)$ & 05 & 84,36 & 421,80 \\
\hline Areia fina $\left(\mathrm{m}^{3}\right)$ & 03 & 56,00 & 168,00 \\
\hline Pedra $\left(\mathrm{m}^{3}\right)$ & 03 & 89,54 & 268,62 \\
\hline Ferro 3/8 (barra $12 \mathrm{~m}$ ) & 25 & 30,51 & 762,75 \\
\hline Ferro 5/16 (barra $12 \mathrm{~m}$ ) & 30 & 20,88 & 626,40 \\
\hline Arame cozido $(\mathrm{kg})$ & 10 & 6,60 & 66,00 \\
\hline Prego 18/24 (pacote $1 \mathrm{~kg}$ ) & 06 & 6,50 & 39,00 \\
\hline Tábua de cambará $3 \mathrm{~m}$ (unid.) & 15 & 30,00 & 450,00 \\
\hline Tábua de cambará 3,5 m (unid.) & 04 & 35,00 & 140,00 \\
\hline Tábua de cambará 4 m (unid.) & 08 & 40,00 & 320,00 \\
\hline Tábua de cambará 4,5 m (unid.) & 02 & 45,00 & 90,00 \\
\hline \multicolumn{4}{|l|}{ ELÉTRICA } \\
\hline Fio sólido (rolo $50 \mathrm{~m}$ ) & 01 & 24,00 & 37,50 \\
\hline Soquete (unid.) & 02 & 3,50 & 7,00 \\
\hline Interruptor (unid.) & 01 & 12,60 & 12,60 \\
\hline Lâmpada fluorescente (unid.) & 02 & 11,20 & 22,40 \\
\hline \multicolumn{4}{|l|}{ ACABAMENTO } \\
\hline Janela (unid.) & 01 & 227,92 & 227,92 \\
\hline Porta 210X090 (unid.) & 01 & 118,70 & 118,70 \\
\hline Fechadura (unid.) & 01 & 38,78 & 38,78 \\
\hline
\end{tabular}




\begin{tabular}{|c|c|c|c|}
\hline Batente da porta (unid.) & 01 & 148,00 & 148,00 \\
\hline Pia com coluna (unid.) & 01 & 105,87 & 105,87 \\
\hline Torneira (unid.) & 01 & 72,90 & 72,90 \\
\hline \multicolumn{4}{|l|}{ ENCANAMENTO } \\
\hline Sifão (unid.) & 01 & 5,25 & 5,25 \\
\hline Cotovelo 50 (unid.) & 02 & 4,21 & 8,42 \\
\hline Cola (unid.) & 01 & 4,27 & 4,27 \\
\hline Cotovelo azul 3/4 (unid.) & 01 & 5,21 & 5,21 \\
\hline Cotovelo marrom $3 / 4$ (unid.) & 02 & 0,60 & 1,20 \\
\hline Cano esgoto 90X50 (unid.) & 01 & 5,25 & 31,50 \\
\hline Cano marrom 3/4 (barra $6 \mathrm{~m}$ ) & 01 & 2,18 & 13,08 \\
\hline \multicolumn{4}{|l|}{ TELHADO } \\
\hline Telha de barro & 600 & 1,43 & 858,00 \\
\hline Prego 22/48 (pacote $1 \mathrm{~kg}$ ) & 03 & 6,50 & 19,50 \\
\hline Viga de garapa 5X11X3 (unid.) & 30 & 33,00 & 990,00 \\
\hline Viga de garapa 5X15X3 (unid.) & 06 & 48,00 & 288,00 \\
\hline Viga de garapa 5X11X4 (unid.) & 10 & 44,00 & 440,00 \\
\hline Viga de garapa $5 \times 11 \times 5$ (unid.) & 05 & 55,00 & 275,00 \\
\hline Viga de garapa 5X15X5 (unid.) & 05 & 80,00 & 400,00 \\
\hline Sarrafo de garapa 2,3X5X1(unid.) & 120 & 2,60 & 312,00 \\
\hline \multicolumn{4}{|l|}{ PINTURA } \\
\hline Tinta (litros) & 02 & 22,00 & 44,00 \\
\hline Água rás (litros) & 01 & 7,50 & 7,50 \\
\hline Verniz (litros) & 01 & 20,00 & 20,00 \\
\hline Pincel (unid.) & 02 & 4,50 & 9,00 \\
\hline Rolo pequeno (unid.) & 02 & 3,00 & 6,00 \\
\hline \multicolumn{4}{|l|}{ Subtotal } \\
\hline otal & & & 8592,17 \\
\hline
\end{tabular}

Em relação a arrecadação de garrafas pet por meio de doações, após a divulgação interna pra professores, funcionários e alunos da Fatec de Presidente Prudente, colocouse postos de coleta em pontos estratégicos da faculdade. A comunidade local atendeu prontamente o pedido. Além disso, uma parceria com o Grupo de Escoteiros Monte Carmelo foi firmada e esta foi essencial para que a arrecadação atingisse o número de 5.000 garrafas doadas em pouco mais de 5 meses de coleta (Figura 4). Estima-se que esta quantidade de garrafas será suficiente para a construção da Casa Pet. 

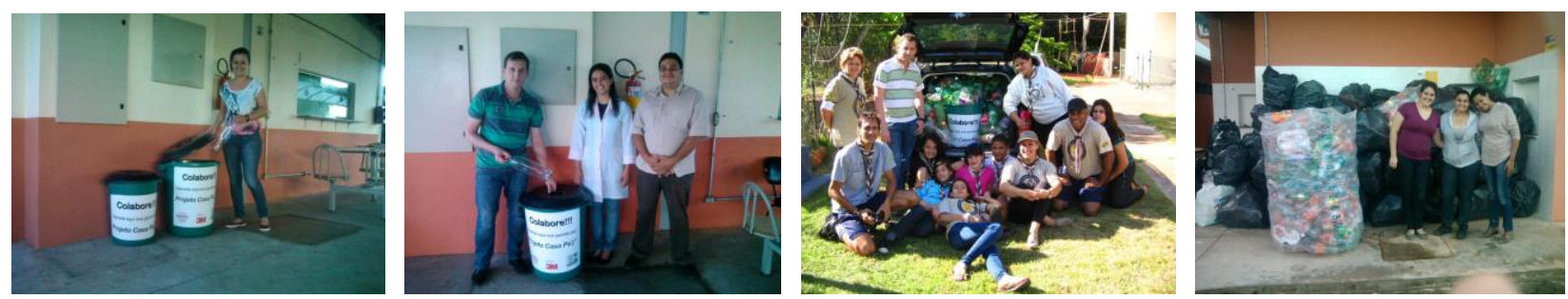

Figura 4. Coleta de garrafas pet.

Na sequência, foi iniciado uma série de tentativas experimentais com o intuito de determinar o material ideal para o preenchimento das garrafas pet que estão sendo utilizadas na construção do ambiente. No primeiro experimento utilizou-se areia lavada que mostrou-se adequada, todavia existe o custo da areia. No segundo experimento, preencheu-se com barro e este não se mostrou eficaz, pois o barro não enrijeceu a garrafa suficientemente para substituir o tijolo na construção. No terceiro experimento, utilizou-se solo-cimento (mistura de barro com cimento) na proporção de $90 \%$ de barro e $10 \%$ de cimento; tal mistura se mostrou eficaz para os propósitos e foi classificada como a solução viável mais barata (Figura 5). Nesta etapa, os estagiários e os escoteiros contribuíram com mão-de-obra voluntária.
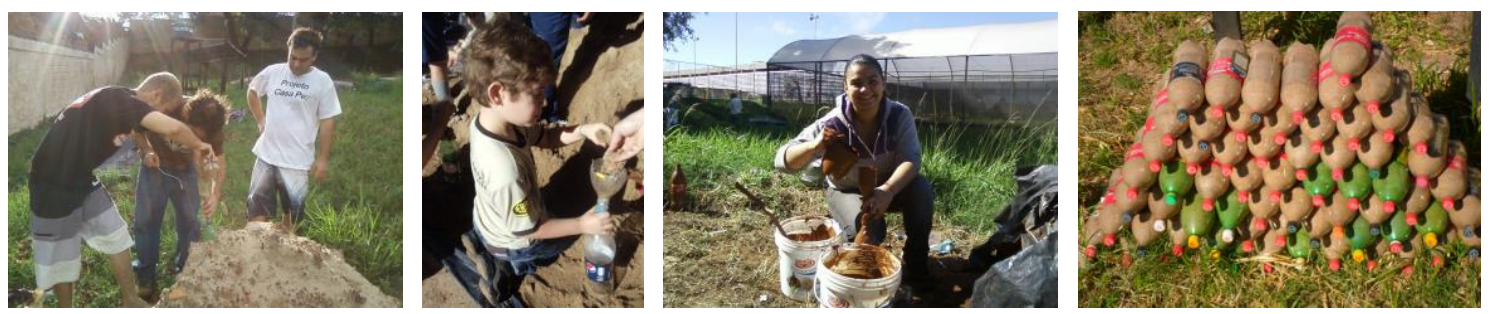

Figura 5. Preenchimento das garrafas pet.

No dia 19 de abril de 2013, por meio da rede social Facebook que é considerada uma das maiores redes sociais da atualidade, criou-se uma página para divulgar e manter as pessoas interessadas no Projeto Casa Pet atualizadas em relação ao seu andamento. Esta página é atualizada quinzenalmente com fatos e fotos sobre o projeto (Figura 6). 


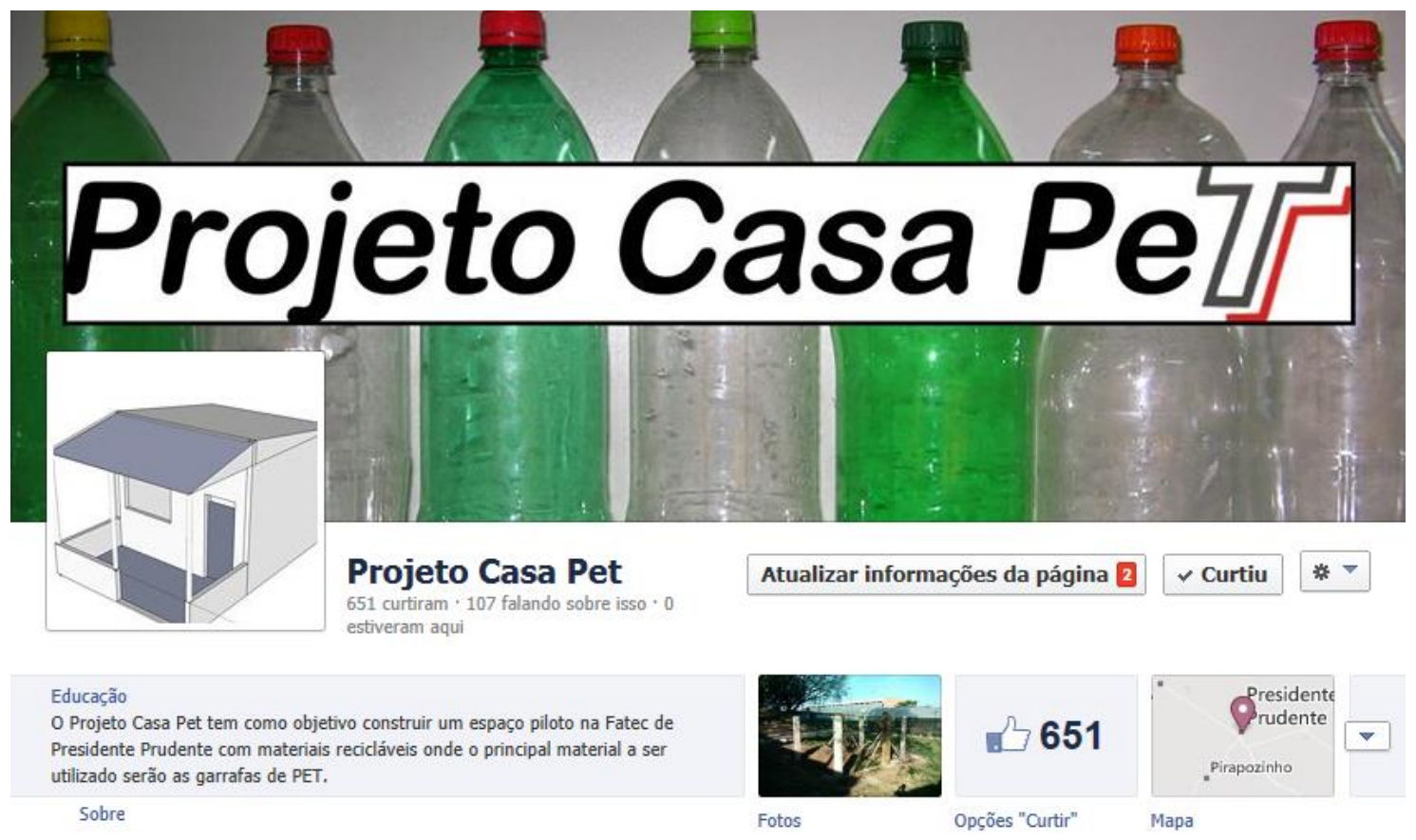

Figura 6. Página do projeto (www.facebook.com/projetocasapet).

Vale ressaltar que a construção da Casa Pet já se encontra em andamento. Com as garrafas preenchidas com areia lavada já foi possível levantar a fundação (Figura 7).
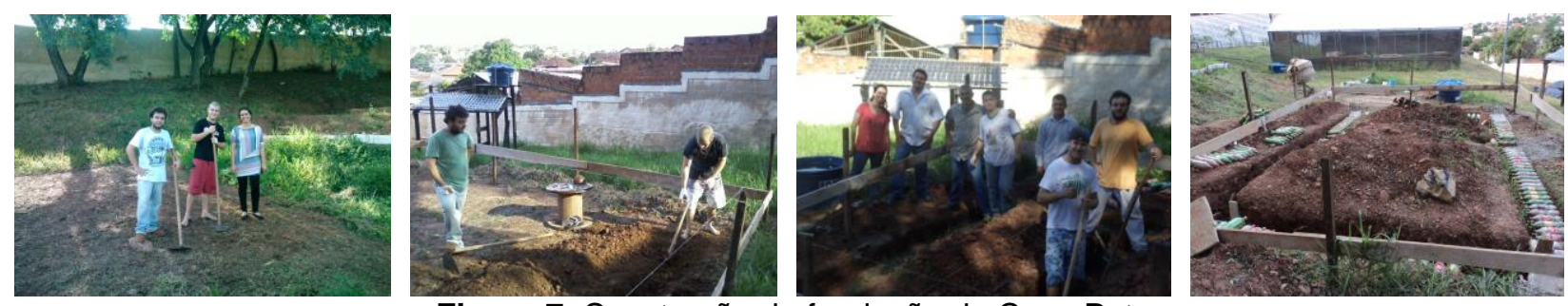

Figura 7. Construção da fundação da Casa Pet.

Também foram construídas 6 colunas (Figura 8), e até esta etapa gastou-se aproximadamente 15 sacos de $50 \mathrm{~kg}$ de cimento, $1 \mathrm{~m}^{3}$ de pedra $1 / 8$ (fina para concreto), 3 $\mathrm{m}^{3}$ de areia fina e 500 garrafas pet preenchidas com areia lavada. 

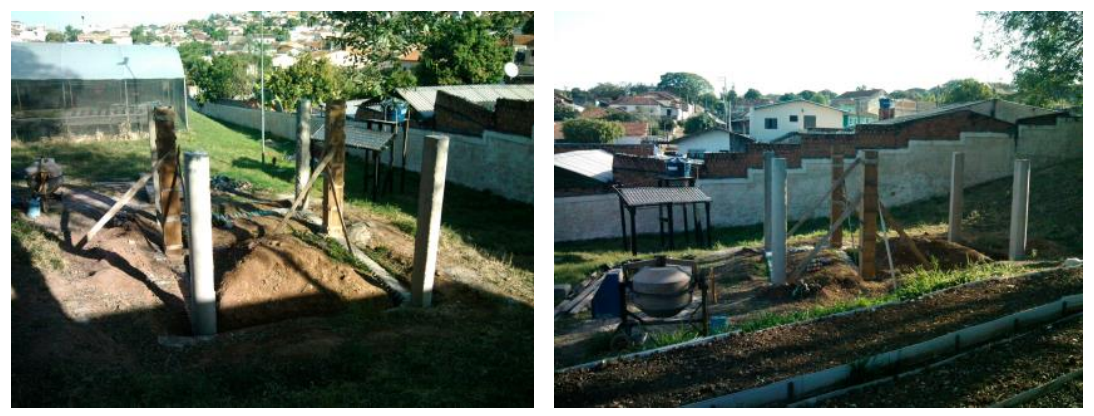

Figura 8. Colunas da Casa Pet.

$\mathrm{Na}$ construção da fundação e das 6 colunas gastou-se mais do que o previsto, principalmente cimento, pois o alicerce e as colunas foram reforçadas para que no futuro possa ser instalado um telhado verde sobre a Casa Pet.

\section{CONCLUSÕES}

Neste trabalho comprovou-se que a garrafa pet pode substituir o tijolo em construções, e considerando a possibilidade de adquiri-las por meio de doações, o custo é se torna viável. Além disso, constatou-se que preenchimento com solo-cimento é eficaz e tem baixo custo, pois para esse fim, só necessita de $10 \%$ de cimento em sua composição.

Percebeu-se que o Projeto Casa Pet tem despertado o interesse de pessoas de diversos locais do Brasil e até mesmo de outros países. Tal afirmação baseia-se na adesão de mais de 650 pessoas na página do projeto hospedada no endereço eletrônico www.facebook.com/projetocasapet.

Para trabalhos futuro, pretende-se comprovar que o este tipo de construção de ambiente é uma alternativa viável tanto do ponto de vista econômico quanto do ponto de vista ambiental. Além disso, será elaborado um manual para que pessoas interessadas neste tipo de construção possa replica-la. Também será instalado um aquecedor solar confeccionado com materiais recicláveis cujos estudos estão sendo desenvolvidos no Laboratório de Conforto Térmico da UNESP - Campus Experimental de Tupã, colaborador com projetos da Fatec de Presidente Prudente. 


\section{AGRADECIMENTOS}

Os autores agradecem à FATEC de Presidente Prudente pelo apoio institucional e pela permissão do início da construção da Casa Pet nas dependências da faculdade, ao Instituto 3M de Inovação Social pelo fomento destinado à realização do Projeto Casa Pet, ao Grupo de Escoteiros Monte Carmelo pela parceria firmada, e à Empresa Júnior da FATEC de Presidente Prudente por possibilitar a participação de estagiários discentes da instituição no projeto.

\section{REFERÊNCIAS}

ABIPET - Associação Brasileira de Indústria do PET. O que é PET? Disponível em: <http://www.abipet.org.br/index.html?method=mostrarlnstitucional\&id=81>. Acesso em: 23 mar. 2012.

ABIPET - Associação Brasileira de Indústria do PET. 7ํㅡㄹ Censo da reciclagem de PET no Brasil 2010. 2011. Disponível em:

<http://www.abipet.org.br/index.html?method=mostrarDownloads\&categoria.id=3>. Acesso em: 23 mar. 2012.

OLIVEIRA, T. M.; CASTRO, P. F. Aproveitamento de rejeito plástico como agregado em concreto asfáltico. In: $V$ Congresso Brasileiro de Engenharia Civil. UFJF. Juiz de Fora, 2002.

WIEBECK, H.; HARADA, J. Plásticos de engenharia: Tecnologia e Aplicações. Artliber. São Paulo, 2005.

ZANIN, M.; MANCINI, S. D. Resíduos plásticos e reciclagem: aspectos gerais e tecnologia. Edufscar. São Carlos, 2004. 